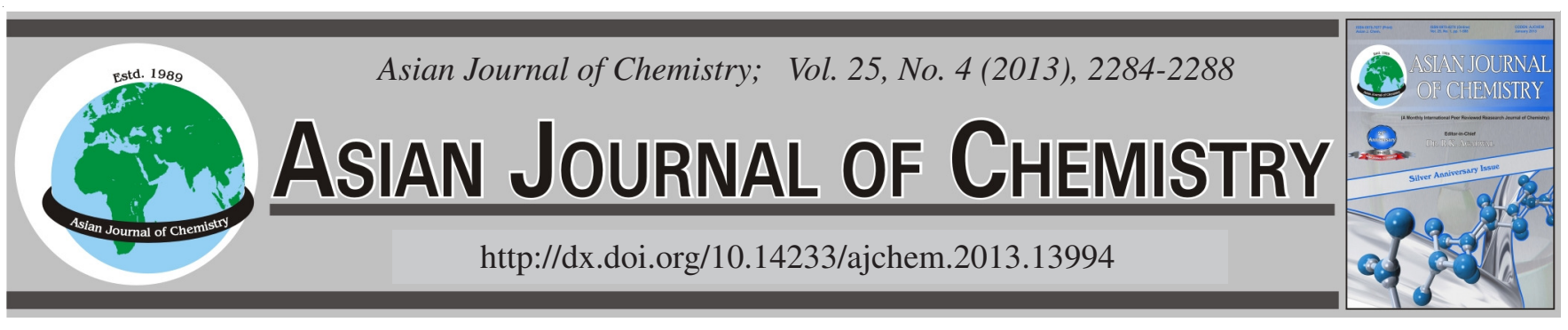

\title{
Photodegradation of Fipronil in Natural Water by High Intensity UV Light Under Laboratory Conditions
}

\author{
JaVAd Gharehdaghy Mianjy* and Babak NAHRi Niknafs
}

Abyek Chemical Complex, Pesticides Research and Development Laboratories, Abyek, Iran

*Corresponding author: E-mail: yimprover@yahoo.com

\begin{abstract}
Fipronil is a phenylpyrazole insecticide which is on decomposition produced photoproducts in environment after using in applications such as rice culture, turf grass management and residential pest control. In this study, the photolysis behaviour of fipronil was investigated in natural water of a river in north Iran by high intensity UV light under laboratory conditions. The results showed that fipronil was photodegraded rapidly and its primary product was fipronil-desulfinyl, which was unstable under the condition of this study. The photodegradation could be described by the pseudo first order reaction kinetics equation. The correlation coefficient $\mathrm{r}^{2}$ and the observed pseudo first order rate constant were 0.923 and $0.0205 \mathrm{~s}^{-1}$, respectively. In the presence of humic acid or hydrogen peroxide, the rate of photodegradation was increased, indicating both of them were photosensitizers for the photodegradation of fipronil. The major photoproducts were identified by GC-MS analysis. On the basis of the structurally identified photoproducts a possible degradation pathway is proposed for the photolysis of fipronil in natural water.
\end{abstract}

Key Words: Fipronil, Photodegradation, Humic acid, Hydrogen peroxide, Regent, Environmental fate.

\section{INTRODUCTION}

Fipronil (5-amino-3-cyano-1-[2,6-dichloro-4(trifluoromethyl)phenyl]-4-[(trifluoromethyl)sulfinyl]pyrazole) (Fig. 1) is a broad spectrum phenylpyrazole insecticide, developed by Rhône-Poulenc Agro in 1987 and registered in the United Stated in $1996^{1}$. Fipronil has been demonstrated to block GABA-gated chloride channel and interfere with central nervous system of insects ${ }^{2}$. Therefore, it can be used to control a wide range of insects, such as mosquito, locust, fleas, termites and click beetles ${ }^{3-5}$. Fipronil with a trade name as regent registered and known as an insecticide in Iran in 1998 that produced exclusive in Abyek chemical complex with capacity 1200 MT in year. The granular product of fipronil is most persistent of its formulations in water ${ }^{6}$. Hereupon, Regent $2 \mathrm{Gr}$ ( $0.2 \%$ fipronil) is used in Iranian rice fields to control rice stem borers with dosage $20 \mathrm{Kg} / \mathrm{Hectare}$ ( $40 \mathrm{~g}$. active ingredient in hectare). Because of its environmental effect and human health, due to its increasing consumption, it is important to investigate the photodegradation of fipronil in surface water.

Previous studies ${ }^{7,8}$ have shown that fipronil on degradation in aqueous solution under natural condition is mainly photolysis and hydrolysis and photolysis is greater than hydrolysis. Bobé et $a .^{7}$ observed that the photodegradation process under a xenon lamp corresponded to a desulfinylation and an oxidation. Nigm et al. ${ }^{9}$ elucidated two fipronil photodegradation pathways. Raveton et al. ${ }^{10}$ demonstrated that fipronil was converted into fipronil-desulfinyl under sunlight or low intensity UV lamp and a large of minor photoproducts were also observed.<smiles>N#Cc1cn(-c2c(Cl)cc(C(F)(F)F)cc2Cl)c(N)c1S(=O)C(F)(F)F</smiles>

Fig. 1. Chemical structures of fipronil

This study was carried out to better understanding the photolysis behaviour of fipronil under high intensity UV light under laboratory conditions. The photodegradation of fipronil as well as its products in aqueous solution under the radiation 
of a high-voltage xenon arc lamp $(1500 \mathrm{~W})$ were investigated. As a main constitute in natural water, the effects of humic acid to the photodegradation of fipronil was studied. The influence of hydrogen peroxide, which is usually used as a photosensitizer to promote the artificial degradation of many organics, was also verified.

\section{EXPERIMENTAL}

Analytical grade standard of fipronil (97.5\% purity), fipronil-desulfinyl (100\% purity) of high purity was obtained from BASF and was used without further purification, fipronil granule (regent $0.2 \% \mathrm{Gr}$ ) was a gift from Abyek chemical complex and all the chemicals and solvents (acetonitrile, $n$ hexane, humic acid, hydrogen peroxide) were obtained from E-Merck (Darmstadt, Germany).

Natural water used in the experiments was collected from North Iran and was natural water of Babolrood river. The natural water sample collected from the top meter of water body in 2.5-L pre-cleaned amber glass bottle and stored at $4{ }^{\circ} \mathrm{C}$ prior to use. Water sample was used without previous treatment and filtration. Physicochemical characteristics of sample of Babolrood river natural water are given in Table-1.

\begin{tabular}{|c|c|c|c|c|c|c|}
\hline \multicolumn{7}{|c|}{$\begin{array}{c}\text { TABLE-1 } \\
\text { PHYSICOCHEMICAL PROPERTIES OF THE } \\
\text { SELECTED NATURAL WATERS }\end{array}$} \\
\hline Water type & $\mathrm{pH}$ & $\begin{array}{c}\text { Conductivity } \\
(\mu \mathrm{S} / \mathrm{cm})\end{array}$ & $\begin{array}{c}\mathrm{TDS}^{1} \\
(\mathrm{mg} / \mathrm{L})\end{array}$ & $\begin{array}{c}\mathrm{TOC}^{2} \\
(\mathrm{mg} / \mathrm{L})\end{array}$ & $\begin{array}{c}\text { Salinity } \\
(\%)(\%)\end{array}$ & $\begin{array}{c}\mathrm{No}_{3}^{-} \\
(\mathrm{mg} / \mathrm{L})\end{array}$ \\
\hline $\begin{array}{l}\text { Babolrood } \\
\text { river }\end{array}$ & 7.81 & 382 & 208 & 2.93 & 0.4 & 3.28 \\
\hline
\end{tabular}

Reactor: The photochemical stability of fipronil was tested using a Sunset CPS+ photo simulator from Heraeus (Hanau, Germany), equipped with a xenon arc lamp (1500 W) and special glass filters restricting the transmission of wavelength below $290 \mathrm{~nm}$. The light source was on the top of the reactor and average irradiation intensity of $750 \mathrm{~W} / \mathrm{m}^{2}$ was maintained throughout the experiments measured by an internal radiometer. Chamber and black panel temperatures were regulated by pressurized air-cooling circuit and monitored using thermocouples supplied by the manufacturer. The temperature of samples did not exceed $25^{\circ} \mathrm{C}$ using tap water cooling circuits for the UV-reactor.

Photolysis in natural water under simulated solar irradiation and extraction procedure: Irradiation experiments were carried out by exposing $500 \mathrm{~mL}$ of aqueous solution of fipronil ( $2 \mathrm{mg} / \mathrm{L}$ ) containing $0.2 \%$ sodium azide (for biological degradation resistance) in the reactor and magnetically stirred continuously. After reaching stable intensity, the high-voltage xenon arc lamp was put into the reactor.
Extraction and clean up was carried out as per method of Kumari et al. ${ }^{11}$. Treated water samples $(500 \mathrm{~mL})$ were taken in a separating funnel and $10 \mathrm{~g}$ sodium chloride was added. Then a volume of $4 \mathrm{~mL}$ solution was collected at a regular time interval of $10 \mathrm{~s}$ until $480 \mathrm{~s}$. Fipronil residues and probable photoproducts were extracted by liquid-liquid partitioning thrice with $15 \%$ dichloromethane in hexane.

The extract is passed through sodium sulphate to remove residual water. Combined the organic layers and concentrated to near dryness on a rotary vacuum flash evaporator followed by nitrogen gas manifold evaporator. The process was repeated thrice after adding $5 \mathrm{~mL}$ hexane in order to eliminate the traces of dichloromethane. The final volume $(2 \mathrm{~mL})$ was made in $n$-hexane for analysis. The final sample was stored in the dark place for further analysis.

Effect of humic acid on fipronil photolysis: A certain amount of humic acid was added to the working solution of 2 $\mathrm{mg} / \mathrm{L}$ fipronil, with the final concentration of $5 \mathrm{mg} / \mathrm{L}$. Then a $500 \mathrm{~mL}$ of solution was placed in the reactor. Other steps were the same as given in extraction procedure.

Effect of $\mathrm{H}_{2} \mathrm{O}_{2}$ on fipronil photolysis: A certain amount of hydrogen peroxide was added to the working solution of 2 $\mathrm{mg} / \mathrm{L}$ fipronil, with the final concentration of $5 \mathrm{mg} / \mathrm{L}$. Then a $500 \mathrm{~mL}$ of solution was placed in the reactor. Other steps were the same as given in extraction procedure.

Instrumentation and analytical conditions: A HewlettPackard system consisting of a 5890 GC system equipped with electron capture detector and capillary column HP-1 (30 m $\times$ $0.32 \mathrm{~mm}$ i.d., $0.25 \mu \mathrm{m}$ film thickness of $5 \%$ diphenyl/95 \% dimethyl polysiloxane), a 5971 mass spectrometer. The injector and detector temperatures were set at $280{ }^{\circ} \mathrm{C}$ and $300{ }^{\circ} \mathrm{C}$, respectively. The oven was programmed to increase from $40{ }^{\circ} \mathrm{C}$ (hold for $1 \mathrm{~min}$ ) to $240^{\circ} \mathrm{C}$ (hold for $20 \mathrm{~min}$ ), at a heating rate of $25^{\circ} \mathrm{C} \mathrm{min}{ }^{-1}$. The carrier gas was helium at a flow rate of 1.2 $\mathrm{mL} \min ^{-1}$. The mass spectrometer detector was tuned by maximum sensitivity autotune (Table-2). The following $\mathrm{m} / \mathrm{z}$ values (quantitation ions are bold) were fixed in the electron impact ionization mode by single ion monitoring (SIM): 213, $\mathbf{3 6 7}$ and 369 for fipronil, 333, 369, 388 and 390 for desulfinyl fipronil; 255, 351, 353 and 420 for fipronil sulfide; 308, 390 and $\mathbf{4 0 6}$ for desulfinyl fipronil amide; 213, 365 and 383 for fipronil sulfone; 255, 368, 385 and 387 for fipronil amide ${ }^{12-15}$.

\section{RESULTS AND DISCUSSION}

Photodegradation of fipronil: The exposure of fipronil to a high-voltage xenon arc lamp led to its degradation. A high rate of photodegradation was observed during the first $60 \mathrm{~s}$ and then the rate slowed down (Fig. 2). After $220 \mathrm{~s}$, no fipronil could be detected in aqueous solution. Representation of the rate of photodegradation over time can be given by the pseudo first order reaction kinetic model.

TABLE-2

DATA OF FIPRONIL PHOTODEGRADATION UNDER DIFFERENT CONDITIONS

\begin{tabular}{|c|c|c|c|c|}
\hline Substances in aqueous solution & $\begin{array}{l}\text { Undetected time of } \\
\text { fipronil(s) }\end{array}$ & $\begin{array}{c}\text { Undetected time of } \\
\text { fipronil-desulfinyl(s) }\end{array}$ & $\begin{array}{l}\text { First order reaction } \\
\text { kinetics equation }\end{array}$ & $\begin{array}{l}\text { Observed rate } \\
\text { constant }\left(\mathrm{s}^{-1}\right)\end{array}$ \\
\hline Fipronil (2 mg/L) & 220 & 480 & $y=0.0205 x+1.0738$ & 0.0205 \\
\hline Fipronil $(2 \mathrm{mg} / \mathrm{L})+$ humic acid $(5 \mathrm{mg} / \mathrm{L})$ & 200 & 420 & $y=0.0244 x+1.1495$ & 0.0244 \\
\hline Fipronil $(2 \mathrm{mg} / \mathrm{L})+$ hydrogen peroxide $(5 \mathrm{mg} / \mathrm{L})$ & 90 & 260 & $y=0.0501 x+1.0863$ & 0.0501 \\
\hline
\end{tabular}




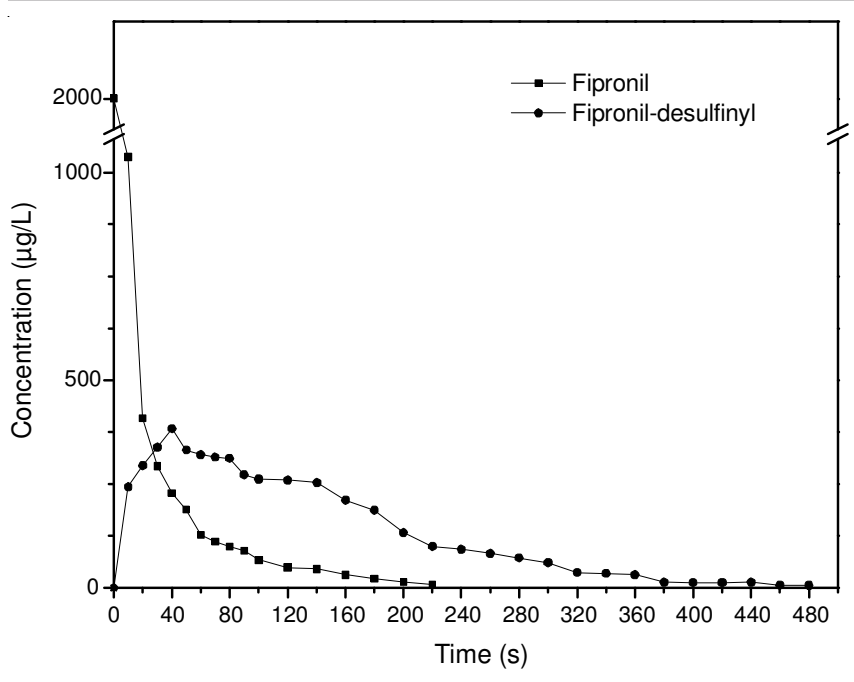

Fig. 2. Concentrations of fipronil and its metabolites at different times

$$
\mathrm{C}_{\mathrm{t}}=\mathrm{C}_{0} \mathrm{e}^{-\mathrm{kt}} \rightarrow \ln \left(\mathrm{C}_{0} / \mathrm{C}_{\mathrm{t}}\right)=\mathrm{kt}
$$

where, $C_{0}=$ initial concentration of fipronil $(\mu \mathrm{g} / \mathrm{L}), \mathrm{C}_{\mathrm{t}}=$ concentration of fipronil $(\mu \mathrm{g} / \mathrm{L}), \mathrm{t}=$ time $(\mathrm{s}), \mathrm{k}=$ fipronil photodegradation rate constant $\left(\mathrm{s}^{-1}\right)$. The curve of natural logarithm of the ratio of $\mathrm{C}_{0}$ to $\mathrm{C}_{\mathrm{t}}\left(\ln \left(\mathrm{C}_{0} / \mathrm{C}_{\mathrm{t}}\right)\right)$ versus time was linear (Fig. 3), with the correlation coefficient $r^{2}$ of 0.923 and the observed rate constant of $0.0205 \mathrm{~s}^{-1}$.

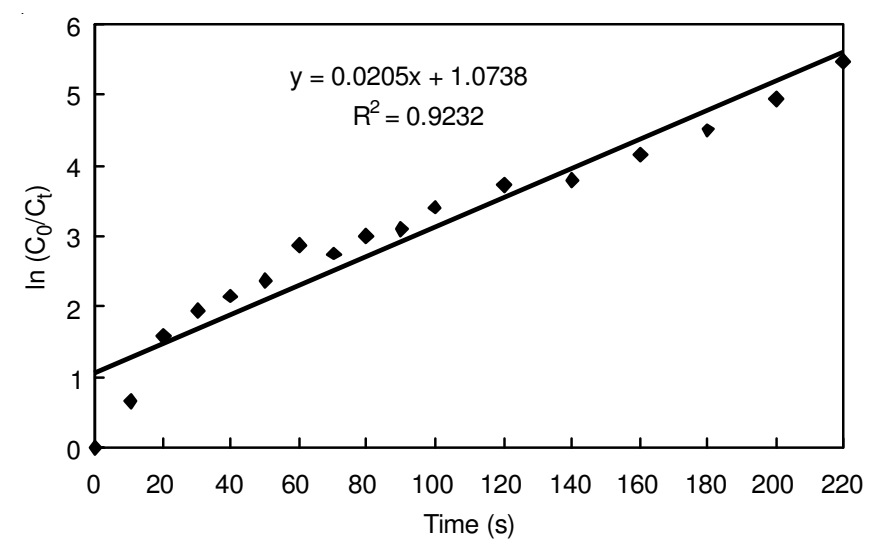

Fig. 3. First order reaction kinetics equation of fipronil degradation

The primary photodegradation product of fipronil was identified to be fipronil-desulfinyl, which concentration increased first and then decreased (Fig. 3). After 480s, fipronildesulfinyl could not be detected, indicating it was completely photodegraded under high intensity UV lamp. The result disagreed with the report of Raveton et al. ${ }^{10}$ which suggested fipronil-desulfinyl was stable under sunlight or low intensity UV light with a degradation of only about $1.4 \%$. However, both studies indicate that light intensity is one of the important factors that influence the stability of fipronil-desulfinyl.

Effect of humic acid on fipronil photolysis: There is a large amount of humic acid in natural waters. Previous studies have shown that humic acid has different effects on the photodegradation of different pesticides. Some are photosensitization, while the others are quenching effect ${ }^{16,17}$. By using this information, the influence of humic acid on fipronil photodegradation rate and photoproducts were investigated.
The results (Fig. 4) showed that in the presence of humic acid, the rate of photodegradation of fipronil in aqueous solution was slightly increased (observed rate constant 0.0244 $\left.\mathrm{s}^{-1}\right)$. After 200s, fipronil could not be detected. The primary photoproduct was still fipronil-desulfinyl, which was completely degraded within 420s. The results indicated humic acid had photosensitive effect on fipronil photolysis. This phenomenon may be explained as follows: under UV irradiation, humic acid would produce reactive oxygen intermediates like singlet oxygen and hydroxyl radicals ${ }^{18,19}$. These reactive oxygen intermediates could act on fipronil to promote its degradation.

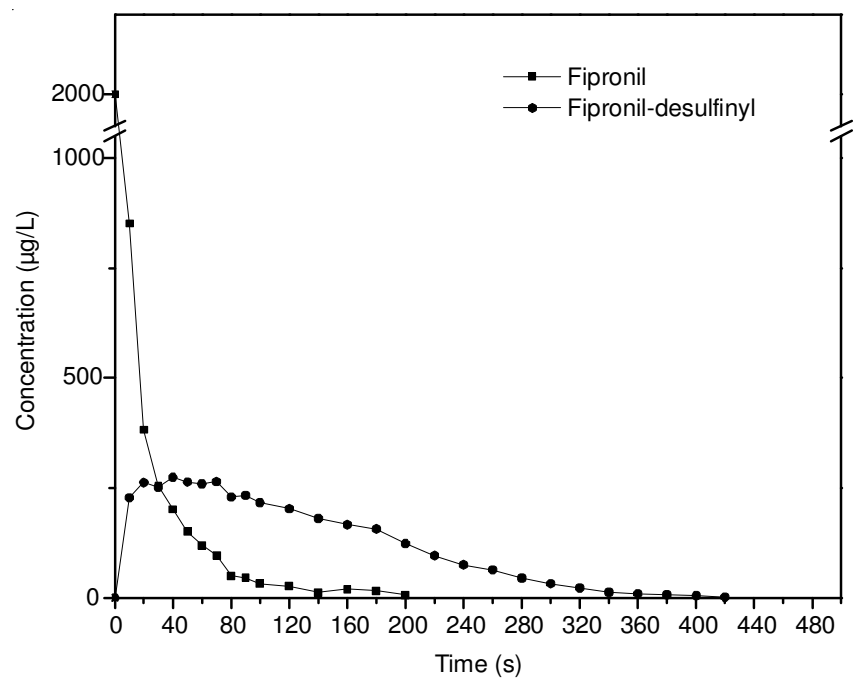

Fig. 4. Concentrations of fipronil and its metabolites at different times in the presence of humic acid $(5 \mathrm{mg} / \mathrm{L})$

Effect of $\mathrm{H}_{2} \mathrm{O}_{2}$ on fipronil photolysis: Previous studies ${ }^{20,21}$ have shown that hydrogen peroxide has sensitization effect on most pesticide photolysis, such as carbofuran and chlorothalonil. Therefore, the influence of hydrogen peroxide on fipronil photodegradation was also investigated in this study. As shown in Fig. 5, fipronil was photodegraded completely within $90 \mathrm{~s}$ (observed rate constant $0.0501 \mathrm{~s}^{-1}$ ) when hydrogen peroxide was present in the reaction mixture. The rate of photodegradation increased with an order of fipronil $<$ fipronil + humic acid $<$ fipronil + hydrogen peroxide, indicating the effect of hydrogen peroxide was more significant than humic acid (Table-2). The photoproducts, fipronil-desulfinyl, degraded quickly and could not be detected after 260s. The results indicated hydrogen peroxide was a good photosensitizer for the photodegradation of fipronil. The results may be explained as follows: hydrogen peroxide was stimulated by UV to generate hydroxyl radicals. Hydroxyl radicals could act on the aromatic ring to promote the decomposition of organic matter ${ }^{22}$.

Identification data for fipronil and its identified photoproducts based on GC-MS: The environmental fate of fipronil is unique in that it is photoactivated to photoproducts that these compounds are several times more lethal to organisms as like rainbow trout, bluegill sunfish and freshwater invertebrates than fipronil and more persistent ${ }^{23,24}$. Fipronil is much more susceptible to breakdown through photolysis rather than hydrolysis in water. Fipronil is readily transformed into its 


\begin{tabular}{|c|c|c|c|}
\hline \multicolumn{4}{|c|}{$\begin{array}{c}\text { TABLE-3 } \\
\text { CAS NAMES FOR CHEMICAL STRUCTURES IN PHOTODEGRADATION PATHWAY }\end{array}$} \\
\hline Common name & Chemical name & m.f. & m.w. \\
\hline Fipronil & $\begin{array}{l}\text { 1-H-Pyrazole-3-carbonitrile,5-amino-1-[2,6-dichloro-4- } \\
\text { (trifluoromethyl)phenyl]-4-[(trifluoromethyl)sulfinyl] }\end{array}$ & $\mathrm{C}_{12} \mathrm{H}_{4} \mathrm{~N}_{4} \mathrm{OSCl}_{2} \mathrm{~F}_{6}$ & 437 \\
\hline Fipronil-desulfinyl & $\begin{array}{l}\text { 1-H-Pyrazole-3-carbonitrile,5-amino-1-[2,6-dichloro-4- } \\
\text { (trifluoromethyl)phenyl]-4-trifluoromethyl }\end{array}$ & $\mathrm{C}_{12} \mathrm{H}_{4} \mathrm{~N}_{4} \mathrm{Cl}_{2} \mathrm{~F}_{6}$ & 389 \\
\hline Fipronil-sulfone & $\begin{array}{l}\text { 1-H-Pyrazole-3-carbonitrile,5-amino-1-[2,6-dichloro-4- } \\
\text { (trifluoromethyl)phenyl]-4-[(trifluoromethyl)sulfonyl] }\end{array}$ & $\mathrm{C}_{12} \mathrm{H}_{4} \mathrm{~N}_{4} \mathrm{O}_{2} \mathrm{SCl}_{2} \mathrm{~F}_{6}$ & 453 \\
\hline Fipronil- sulfide & $\begin{array}{l}\text { 1-H-Pyrazole-3-carbonitrile,5-amino-1-[2,6-dichloro-4- } \\
\text { (trifluoromethyl)phenyl]-4-[(trifluoromethyl)thio] }\end{array}$ & $\mathrm{C}_{12} \mathrm{H}_{4} \mathrm{~N}_{4} \mathrm{SCl}_{2} \mathrm{~F}_{6}$ & 421 \\
\hline Fipronil- amide & $\begin{array}{l}\text { 1-H-Pyrazole-3-carboxylicacid,5-amino-1-[2,6-dichloro-4- } \\
\text { (trifluoromethyl)phenyl]-4-[(trifluoromethyl)sulfinyl] }\end{array}$ & $\mathrm{C}_{12} \mathrm{H}_{6} \mathrm{~N}_{4} \mathrm{O}_{2} \mathrm{SCl}_{2} \mathrm{~F}_{6}$ & 455 \\
\hline $\begin{array}{l}\text { Fipronil- detrifluoromethyl- } \\
\text { sulfinyl }\end{array}$ & $\begin{array}{l}\text { 1-H-Pyrazole-3-carbonitrile,5-amino-1-[2,6-dichloro-4- } \\
\text { (trifluoromethyl)phenyl }\end{array}$ & $\mathrm{C}_{11} \mathrm{H}_{5} \mathrm{~N}_{4} \mathrm{Cl}_{2} \mathrm{~F}_{3}$ & 321 \\
\hline
\end{tabular}

TABLE-4

IDENTIFICATION DATA FOR FIPRONIL AND ITS IDENTIFIED PHOTOPRODUCTS BASED ON GC-MS

\begin{tabular}{lccc}
\hline Compound & $\mathrm{R}_{\mathrm{t}} \pm \mathrm{SD}(\mathrm{min})$ & Abs $(\mathrm{nm})$ & $\mathrm{m} / \mathrm{z}$ \\
\hline Fipronil & $15.25 \pm 0.03$ & 290 & $213,367,369$ \\
Fipronil- sulfone & $23.65 \pm 0.11$ & 290 & $213,365,383$ \\
Fipronil- sulfide & $14.62 \pm 0.03$ & 290 & $255,351,353,420$ \\
Fipronil-desulfinyl & $12.21 \pm 0.02$ & 290 & $333,369,388,390$ \\
Fipronil-detrifluoromethyl-sulfinyl & $14.36 \pm 0.03$ & 290 & $213,320,321$ \\
Fipronil-amide & $24.17 \pm 0.12$ & 290 & $255,368,385,387$ \\
\hline
\end{tabular}

photoproducts when exposed to sunlight. In present study five photodegradation products (Table-3) were identified by GC-MS analysis and Table-4 shows the constituents of the major photoproducts. The major photoproduct was a derivative of $m / z, 48$ less than fipronil itself (molecular mass of 437). This M-48 photoproduct is equivalent in mass to loss of the sulfinyl moiety and was identified as fipronil-desulfinyl. There was also one primary photoproduct of fipronil of $\mathrm{m} / \mathrm{z}, 321$ (M-116), identified by MS analysis as the detrifluoromethylsulfinyl derivative.

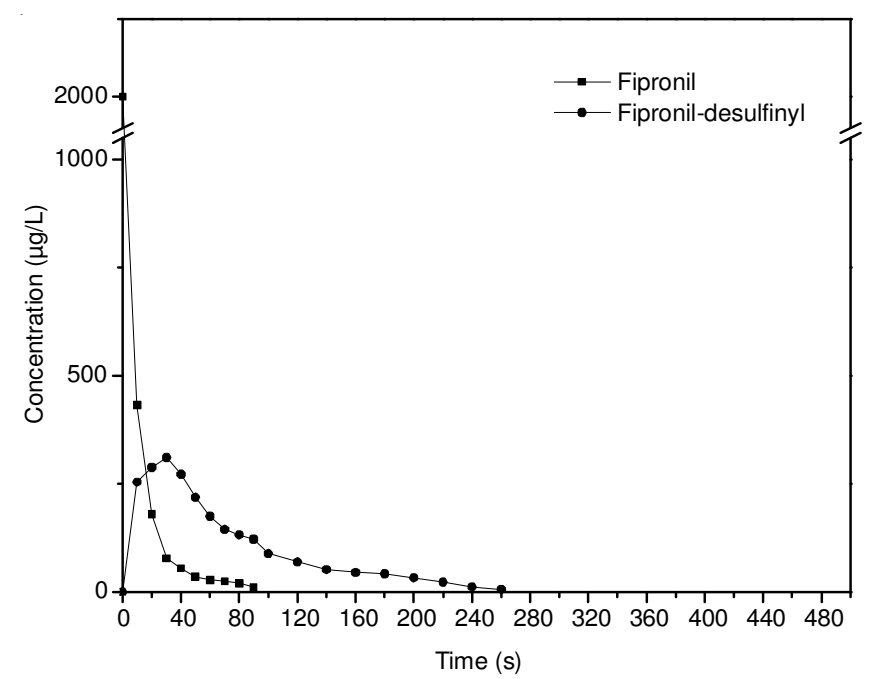

Fig. 5. Concentrations of fipronil and its metabolites at different times in the presence of hydrogen peroxide $(5 \mathrm{mg} / \mathrm{L})$

Photodegradation pathway of fipronil: The results suggest that the photodegradation pathway of fipronil under this study's condition may be as follows: Fipronil was firstly photodegraded into fipronil-desulfinyl and it was further photodegraded thereafter. Formation of fipronil- desulfinyl is possibly due to hydroxyl radicals generated upon irradiation. Photodegradation with extrusion of SO or loss of the trifluoromethyl-sulfinyl moiety does not occur with a fipronil analog lacking the amino and carbonitrile group. Formation of the radical pair shown in Fig. 6, proposed in the direct photolysis of aryl and alkenyl methyl sulfoxides, may be the first step in extrusion of SO from fipronil to give fipronil -desulfinyl. By comparing and referring to other researcher's studies ${ }^{9,10}$, we inferred that fipronil-desulfinyl might be degraded into aniline derivatives or other substances in our experiment. On the basis of the structurally identified photoproducts a possible degradation pathway could be proposed for the photolysis of fipronil in natural water. A possible photodegradation pathway is presented in Fig.7. However, it needs to identify all the photoproducts in order to reveal the detailed pathways.

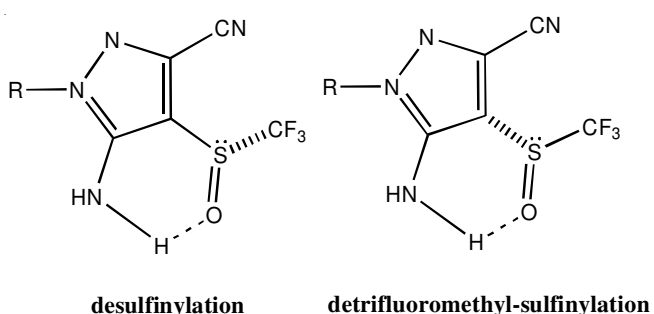

Fig. 6. Partial structures of proposed initial di radical intermediates in photodecomposition of fipronil. (R, 2,6-dichloro-4-trifluoromethylphenyl)<smiles>COC(OC)O[CH]c1cc(C(F)(F)F)cc(Cl)c1N=NCC#N</smiles>

Fig. 7. Suggested pathway of fipronil photodegradation 


\section{Conclusion}

Under the high intensity UV lamp irradiation condition, the photodegradation of fipronil was rapid and followed the first order reaction kinetics. The primary photodegradation product was fipronil-desulfinyl, which would be further degraded under the same condition. Both humic acid and hydrogen peroxide have photosensitization effect on the photodegradation of fipronil, but the effect of hydrogen peroxide was more significant. More studies need to be done to reveal the detailed pathway of fipronil photodegradation.

Conflict of interest: This research is not a part of our normal lecturing, employment, consultation and involvement; and no institution will require any rights from this work. In addition, no patent has been applied nor any commercial right has been given to any company and/or institution and it will not be done later either.

\section{ACKNOWLEDGEMENTS}

The author gratefully acknowledged the support from Abyek Chemical Complex, Pesticides Research and Development Laboratories and also express their appreciation to Mr. Manoochehr Dastour for his assistance in the chemical experiments, basic data and useful advise.

\section{REFERENCES}

1. A.S. Gunasekara and T. Troung, Environmental Fate of Fipronil. California Environmental Protection Agency, pp. 1-28 (2007).

2. L.M. Cole, R.A. Nicholson and J.E. Casida, Pestic. Biochem. Physiol., 46, 47 (1993).

3. J.M. Gaulliard, Phytoma, 488, 59 (1996).
4. D. Schlenk, D.B. Huggett, J. Allgood, E. Bennett, J. Rimoldi, A.B. Beeler, D. Block, A.W. Holder, R. Hovinga and P. Bedient, Arch. Environ. Contam. Txicol., 41, 325 (2001).

5. P.F. Chaton, P. Ravanel, M. Tissut and J.C. Meyran, Ecotoxicol. Rnviron. Saf., 52, 8 (2001).

6. K. Ngim and D.G. Crosby, Environ. Toxicol. Chem., 20, 972 (2001).

7. A. Bobé, P. Meallier, J.F. Copper and C.M. Coste, J. Agric. Food Chem., 46, 2834 (1998).

8. G.N. Zhu, J.T. Wu, Q.K. Liu and J.H. Sun, Chin. J. Pesticide Sci., 2, 52 (2000).

9. K.K. Nigm, S.A. Mabury and D.G. Crosby, J. Agric. Food Chem., 48, 4661 (2000).

10. M. Raveton, A. Aajoud, J.C. Willison, H. Aouadi, M. Tissut and P. Ravanel, Environ. Sci. Technol., 40, 4151 (2006).

11. B. Kumari, V.K. Madan and T.S. Kathpal, India Environ. Monit. Assess., 136, 239 (2007).

12. T.J. Husen, N.A. Spomer and S.T. Kamble, Bull. Environ. Contamin. Toxicol., 82, 605 (2009).

13. M.Z. Lacroix, S. Puel, P.L. Toutain and C. Viguie, J. Chromatogr. B, 878, 1934 (2010).

14. C.S.M. Masutti and A.R. Mermut, J. Environ. Sci. Health B, 42, 33 (2007).

15. J.L. Vilchez, A. Prieto, L. Araujo and A. Navalon, J. Chromatogr. A, 919, 215 (2001).

16. M. Kamiya and K. Kameyama, Chemosphere, 36, 2337 (1998).

17. H. Zheng and C. Ye, Bull. Environ. Contam. Toxicol., 67, 601 (2001).

18. K. Hustert, P.N. Moza and A. Kettrup, Chemosphere, 38, 3423 (1999).

19. W.J. Tan, J.S. Wang, A.Z. Ding and F.S. Li, J. Agro-Environ. Sci., 28, 135 (2009).

20. F.J. Benitez, J. Beltran-Heredia, T. Gonzalez and F. Real, Ind. Eng. Chem. Res., 34, 4099 (1995).

21. X.D. Li, R.M. Hua, F. Tang and J. Tang, J. Anhui Agric. Sci., 37, 5097 (2009).

22. H.D. Burrows, L.M. Canle, J.A. Santaballa and S. Steenken, J. Photochem. Photobiol. B: Biol., 67, 71 (2002).

23. J.E. Casida, D. Hainzl, L.M. Cole, Chem. Res. Toxicol., 11, 1529 (1998).

24. U.S. Environmental Protection Agency, Federal Register/Rules and Regulations, vol. 63 (137), pp. 38483-38495 (1998). 